\title{
The Participation of Filament Anastomosis in the Developmental Cycle of Nostoc muscorum, a Blue-Green Alga
}

\author{
By N. LAZAROFF* AND W. VISHNIAC $\dagger$ \\ Department of Microbiology, Yale University, New Haven, Connecticut, U.S.A.
}

(Received 23 May 1961)

SUMMARY

During the resumption of development in cultures of Nostoc muscorum A, grown in the dark, and then exposed to light, cellular attachment occurs. This process is believed to be prerequisite for the formation of heterocystous filaments. The significance of anastomosis in the developmental cycle of Nostoc is discussed and a tentative scheme for an alternation of sporogenous and heterocystous generations is presented.

\section{INTRODUCTION}

During a study of the growth of the blue-green alga Nostoc muscorum $\mathrm{A}$ in the dark, it had been noted that inhibition of growth, in darkness, is accompanied by an interruption of the normal sequence of morphological development which can be observed in cultures grown in the light. Exposing dark grown cultures to light of low intensity allowed resumption of growth and synchronous differentiation of the various stages in the development of this organism. The details of the complex cycle of development, its relationship to light, as well as the techniques for cultivating $N$. muscorum $\mathbf{A}$ have been described in another paper (Lazaroff \& Vishniac, 1961).

\section{METHODS}

The basal medium consisted of the following substances dissolved in 11 . of distilled water: $\mathrm{K}_{2} \mathrm{HPO}_{4}, 0.15 \mathrm{~g}$; $\mathrm{MgSO}_{4} .7 \mathrm{H}_{2} \mathrm{O}, 0.20 \mathrm{~g}$.; $\mathrm{CaCl}_{2} .2 \mathrm{H}_{2} \mathrm{O}, 0.025 \mathrm{~g}$.; $\mathrm{Na}_{2} \mathrm{SiO}_{3}, 0.025$ g.; $\mathrm{FeCl}_{3} .6 \mathrm{H}_{2} \mathrm{O}, 2 \cdot 0 \mathrm{mg}$.; $\mathrm{MnCl}_{2} .4 \mathrm{H}_{2} \mathrm{O}, 0.4 \mathrm{mg}$.; $\mathrm{Na}_{2} \mathrm{MoO}_{4} \cdot 2 \mathrm{H}_{2} \mathrm{O}$, 0.4 mg.; $\mathrm{H}_{3} \mathrm{BO}_{3}, 0.6 \mathrm{mg}$.; $\mathrm{CuSO}_{4} . \mathrm{H}_{2} \mathrm{O}, 0.04 \mathrm{mg}$.; $\mathrm{ZnSO}_{4} .7 \mathrm{H}_{2} \mathrm{O}, 0.04 \mathrm{mg}$. The pH was adjusted to $7 \cdot 2$ before autoclaving.

The sequence of developmental changes was most conveniently studied by periodic observation of micro-colonies growing in a thin layer of medium solidified with $\mathbf{0 . 9} \%$ agar. The cooled but still molten agar was seeded with a Nostoc suspension prepared by homogenization for 30 sec. in a sterile Waring micro-blendor cup. Four ml. of seeded medium were pipetted into inverted Carrel flasks so that a thin layer adhered to the upper plane surface of the flask after solidification. The flasks were generally placed in the dark for 2 weeks, then exposed to continuous illumina-

\footnotetext{
* Present address: British Columbia Research Council, University of British Columbia, Vancouver 8, B.C., Canada.

$\dagger$ Present address : Department of Biology, University of Rochester, Rochester 20, N.Y., U.S.A.
} 
tion of 50-100 ft.c. from a cool white fluorescent source. The developmental phenomena occurring at or just below the interface of the agar with the wall of the Carrel flask could be observed and plotographed at high magnification.

\section{RESULTS}

Although growth in complete darkness in culture media containing glucose or sucrose fails to display normal development, the stage of interrupted development may differ according to the ou tline given in Table 1. If inocula are grown in the dark, subsequent transfer to media containing glucose or sucrose followed by incubation in complete darkness yields growth which is maintained at the aseriate stage of development. Plate 1, ig. 1, shows Nostoc muscorum grown in this manner which results in the formation of clumps of large cells, each clump derived from a single intercalary cell of the parent hormogonia. Similar development is obtained

\section{Table 1. Effect of origin of i zoculum on the morphology of Nostoc muscorum} in the dark

\begin{tabular}{|c|c|c|}
\hline toculum & $\begin{array}{c}\text { Inoculated } \\
\text { into basal } \\
\text { medium } \\
\text { :upplemented } \\
\text { with }\end{array}$ & $\begin{array}{c}\text { Incubation } \\
\text { period } \\
\text { (days) }\end{array}$ \\
\hline
\end{tabular}

\begin{tabular}{|c|c|c|c|}
\hline $\begin{array}{l}\text { Unwashed pellet from 30-day-old } \\
\text { shake culture, basal medium, } \\
250 \text { ft.c. }\end{array}$ & $\begin{array}{l}1 \% \text { glucose } \\
1 \% \text { sucrose }\end{array}$ & $\begin{array}{l}24 \\
24\end{array}$ & $\begin{array}{l}\text { Aseriate, some filamentation } \\
\text { Opening clusters and motile } \\
\text { trichomes }\end{array}$ \\
\hline $\begin{array}{l}\text { Washed suspension from 14-day- } \\
\text { old shake culture, basal medium, } \\
250 \text { ft.c. }\end{array}$ & $\begin{array}{l}1 \% \text { glucose } \\
1 \% \text { sucrose }\end{array}$ & $\begin{array}{l}24 \\
24\end{array}$ & $\begin{array}{l}\text { Aseriate } \\
\text { Aseriate, some filamentation }\end{array}$ \\
\hline $\begin{array}{l}\text { Washed suspension from } 20 \text {-day- } \\
\text { old culture, basal medium }+1 \% \\
\text { sucrose, } 150 \mathrm{ft} . \mathrm{c} \text {. }\end{array}$ & $\begin{array}{l}1 \% \text { glucose } \\
1 \% \text { sucrose }\end{array}$ & $\begin{array}{l}35 \\
35\end{array}$ & $\begin{array}{l}\text { Aseriate } \\
\text { Aseriate, some filamentation }\end{array}$ \\
\hline $\begin{array}{l}\text { Washed suspension from } 30-\text { day- } \\
\text { old culture, basal medium }+1 \% \\
\text { glucose, } 150 \text { ft.c. }\end{array}$ & $\begin{array}{l}1 \% \text { glucose } \\
1 \% \text { sucrose }\end{array}$ & $\begin{array}{l}33 \\
33\end{array}$ & $\begin{array}{l}\text { Aseriate } \\
\text { Aseriate }\end{array}$ \\
\hline $\begin{array}{l}\text { Loopful from dark grown culture, } \\
\text { basal medium }+1 \% \text { glucose }\end{array}$ & $\begin{array}{l}\% \text { glucose } \\
\% \text { sucrose }\end{array}$ & $\begin{array}{l}33 \\
33\end{array}$ & $\begin{array}{l}\text { Aseriate } \\
\text { Aseriate }\end{array}$ \\
\hline $\begin{array}{l}\text { Loopful from dark grown culture, } \\
\text { basal medium }+1 \% \text { sucrose }\end{array}$ & $\begin{array}{l}\text { \% glucose } \\
\text { ] } \% \text { sucrose }\end{array}$ & $\begin{array}{l}33 \\
33\end{array}$ & $\begin{array}{l}\text { Aseriate } \\
\text { Aseriate }\end{array}$ \\
\hline
\end{tabular}

if a small amount of a homogenized suspension of filaments, grown in the light, is used to inoculate culture media sontaining glucose, which are then incubated in complete darkness. However, if the inoculum has been prepared from Nostoc grown photo-autotrophically or in media containing sucrose in the light, then transferred to media containing sucrose and iacubated in the dark, short filaments are formed (Pl. 1, figs. 2-4). These filaments, which are capable of motility, are derived from the aseriate stage of development kut without the previous differentiation of heterocysts. This mode of development $\mathrm{c}$ )ntrasts with the formation of hormogonia which are derived from heterocystous filaments by fragmentation at the heterocyst (Pl. 1, figs. 5, 6).

When the short motile filaments, produced in the dark, are exposed to continuous illumination at low intensity (20-50 ft.c.), synchronous development does not take 
place. Instead, the short filaments swarm and anastomose, occasionally producing spore-like structures at the point of attachment (Pl. 2, figs. 7-13). Heterocystous filaments are produced in the light following filament fusion. The drawings in Figs. 1 and 2 compare the developmental sequences observed when aseriate packets are exposed to light with the phenomena which occur after the dark-grown short filament forms are similarly exposed.

Continuous observation of the spore-like structures produced after the attachment of filaments has indicated that germination can take place to produce a motile filament. It should be emphasized that in most cases the attachment of filaments occurs without the formation of a specialized structure at the point of attachment. The factors which govern whether the attachment of cells will lead to these sporelike structures or whether directly to filaments which eventually produce heterocysts are unknown.

Whether the enlarged structures are normal formations or teratological does not detract from the significance of their occurrence. Although it is difficult to ascertain whether a physiological connexion occurs between the anastomosing cells during the process of normal heterocystous filament formation, there can be little doubt that the structures which form only after the attachment of filaments proceed from the interaction of the joining cells.

When dark-grown aseriate packets are crushed between slide and coverslip or are dissected with a micro-needle, single cells or chains 2 or 3 cells long are extruded from each packet. If the dark-grown aseriate cultures are incubated at a light intensity of approximately $50 \mathrm{ft} . c$., for periods up to 3 days, fewer short chains and single cells are to be found. After 3 days' illumination, the contents of each packet are converted into a single trichome containing developing heterocysts. In a number of such observations the maturing heterocystous filament occurred in the form of a closed loop. These observations are summarized in Fig. 3.

\section{DISCUSSION}

The synchrony of development which results when aseriate cultures are exposed to light apparently depends on a high incidence of filament fusion taking place among the cells derived from the aseriate stage, thus yielding a homogeneous progeny of heterocystous filaments. In cultures, in which filamentation has taken place in the dark, swarming of the short filaments as well as anastomosis takes place on exposure to light. Therefore the development lacks synchrony, i.e. the population quickly becomes heterogeneous with respect to the stage of development. Not only are heterocystous filaments produced, but also filaments which are capable of fragmentation, spore formation, and anastomosis (Pl. 2, fig. 13).

The relationship of these two modes of development are summarized in Fig. 4 which presents a tentative scheme for the alternation of heterocystous and sporogenous generations.

The short motile trichomes which result from the fragmentation of sporogenous filaments may be regarded as spore germlings produced in situ on their parent filaments. These clearly differ from hormogonia in their mode of subsequent development. It may be noted that Harder $(\mathbf{1 9 1 7} b)$ had described a positive phototaxis for the spore germlings (primary hormogonia) of Nostoc punctiforme but 
apparent photo-indifference of the motile trichomes (secondary hormogonia) produced from heterocystous filaments.

The concept of an alternation of heterocystous and sporogenous generations helps to clarify a long-standing inconsistency in descriptions of the life cycle of the fila-

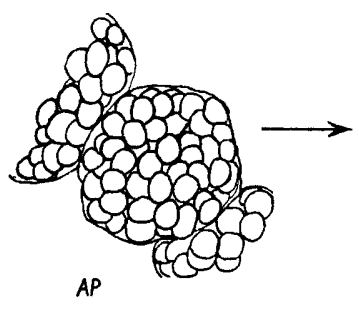

Growth in darkness

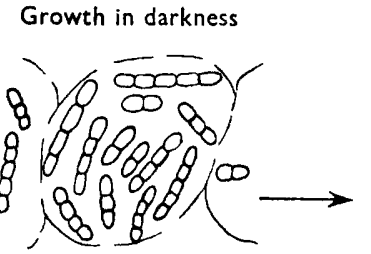

SF

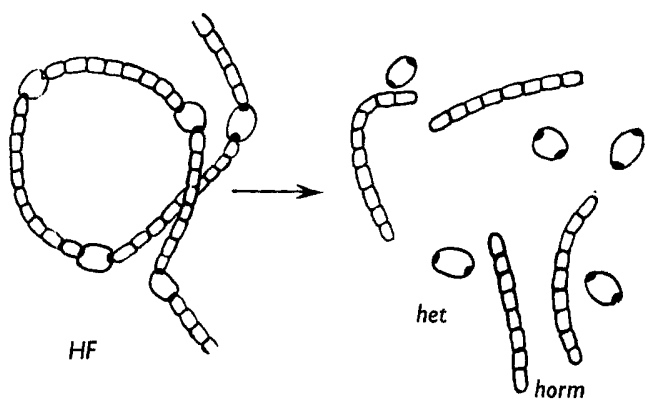

Under continuous illumination

Fig. 1

Under continuous illumination

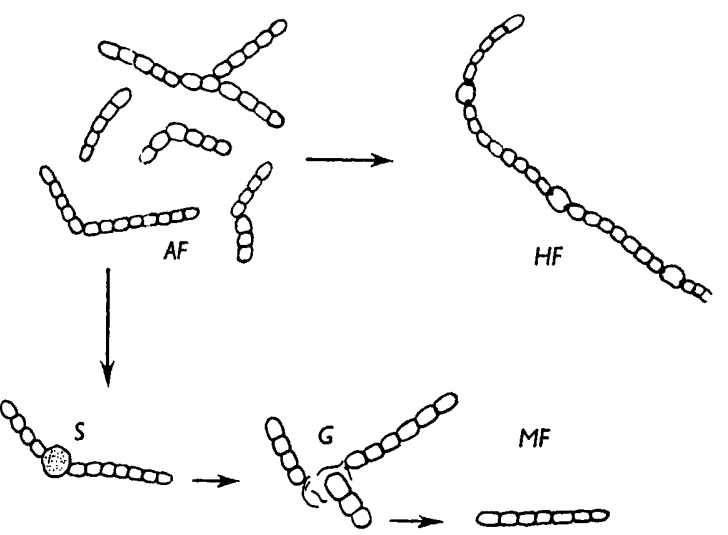

Fig. 2

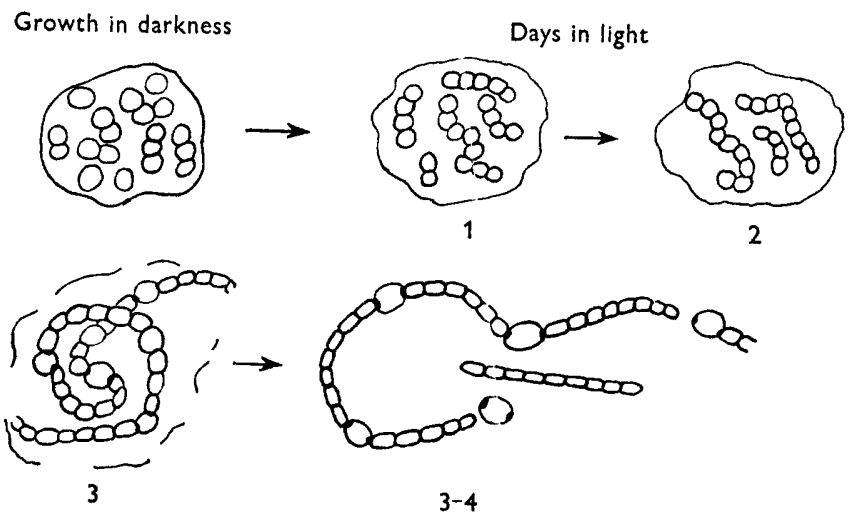

Fig. 3

For legend see facing page. 
mentous blue-green algae. It had been frequently noted that motile trichomes could form by breakage of parent filaments at heterocysts or from the fragmentation of non-heterocystous filaments. In those cases where the further development of hormogonia, derived from a mature heterocystous thallus, was studied, an aseriate stage was produced which eventually differentiated to become a new heterocystous colony (Thuret, 1844; Sauvageau, 1897). Investigators who observed the further development of motile trichomes derived from germinating akinetes reported a different phenomenon (Janczewski, 1874; Harder, 1917 a). The sequence generally involved the elongation of the parent trichome with the formation of heterocysts only from the terminal cells. Eventually the contorted filament fragmented without the participation of heterocysts to produce short filament segments, again capable of motility. It was realized that a heterocystous filament could eventually be produced from a spore, although the developmental sequence was obscure.

The observations of Fogg (1949), that the production of heterocysts in cultures of Anabaena cylindrica is influenced by the presence of certain metabolizable substances, are not inconsistent with the concept of a nostocacean developmental cycle. It has been pointed out in a previous paper (Lazaroff \& Vishniac, 1961) that environmental factors, such as light intensity and the presence of glucose, influence the maintenance of the heterocystous phase of development. At high light intensities, in the presence of glucose, fragmentation of the heterocystous filaments to yield hormogonia ceases, yielding extremely long filaments with abundant intercalary heterocysts.

The results of our investigation indicate that the two types of motile filaments produced by Nostoc muscorum A may not be equivalent structures. The first type, for which the term 'hormogone' should be reserved, produces heterocystous colonies.

Figs. 1-3. Comparison of the developmental sequence, after light exposure, of dark-grown aseriate forms with that of short filament forms.

Fig. 1. Each aseriate packet $(A P)$ is enclosed in a firm gelatinous envelope and, when exposed to light, forms a single heterocystous filament $(\boldsymbol{H} F)$. The heterocystous filament fragments at the heterocysts (het), yielding free intercalary heterocysts and gliding hormogonia (horm).

Fig. 2. The short filaments $(S F)$, produced in the dark on media containing sucrose, are held within a diffuse gelatinous membrane. After illumination these short filaments glide out of their gelatinous matrix and anastomose (anastomosing filaments $A F$ ). The filaments resulting from anastomosis most frequently elongate by cell division and form heterocysts (heterocystous filaments $H F$ ). In some instances one or more spore-like structures $(S)$ are produced from the anastomosing cells. These structures may germinate $(G)$, and yield a short filament which elongates by cell division and differentiates into a motile filament $(M F)$.

Fig. 3. Development within aseriate packets after exposure to light. Material from darkbrown aseriate cultures in liquid media was examined immediately after removal from darkness and at daily intervals during development. 'The contents of the developing packets were observed by gently crushing the packets between slide and coverslip or by dissection with a micro-needle. Immediately after removal from darkness the packets contained single cells or very short chains, 2-3 cells long. In the light each packet with time contained a decreasing number of chains, each of increased length. After 3-4 days the enclosing membranes of the original packets dissolved. At that time the cells in each packet formed a single heterocystous filament, occasionally in the shape of a closed loop. These filaments then underwent fragmentation with the liberation of heterocysts and hormogonia. 


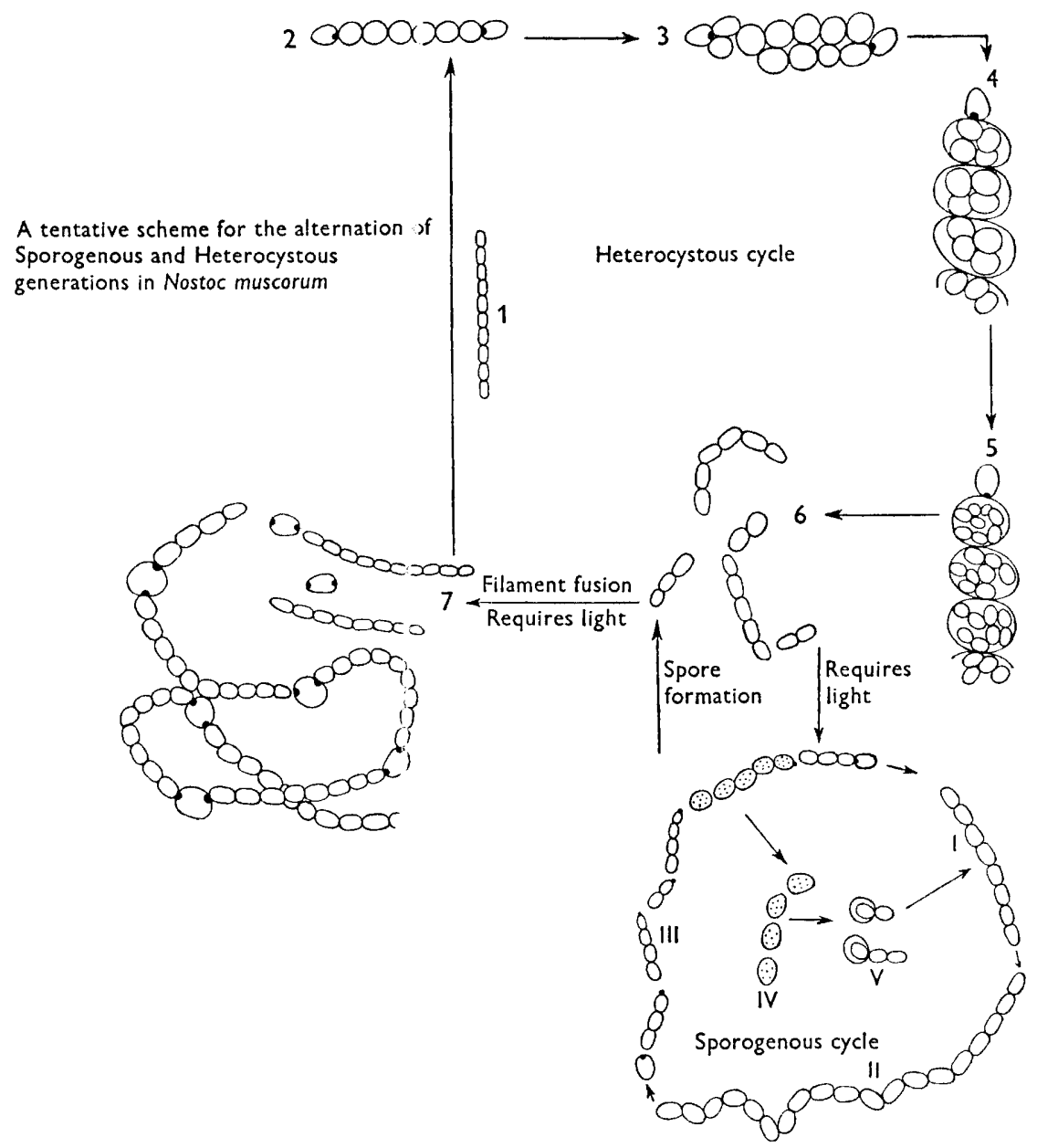

Fig. 4. For legend see facing page.

The second type, which develop: in a manner similar to 'spore germlings' may form a heterocystous colony after a frocess of filament anastomosis has taken place, but alternatively may swarm, grow in length, fragment, or sporulate, maintaining a developmental sequence independent of the heterocystous cycle.

Supported by grants from the National Science Foundation and the National Institutes of Health. A portio 1 of this work was carried out by one of us (N.L.) with the support of pre-doctorcl fellowships from the National Science Foundation and the U.S. Public Health Service. This work forms part of a dissertation submitted by N.L. to the Gradua se School of Yale University as requirement for the degree of Doctor of Philosophy. 


\section{REFERENCES}

Fogg, G. E. (1949). Growth and heterocyst production in Anabaena cylindrica Lemm. II. In relation to carbon and nitrogen metabolism. Ann. Bot., N.S., 13, 241.

HARDER, R. (1917a). Ernährungsphysiologische Untersuchungen an Cyanophyceen, hauptsächlich dem endophytischen Nostoc punctiforme. Z. Bot. 9, 145.

Harder, R. $(1917 b)$. Über die Beziehung des Lichts zur Keimung von Cyanophyceensporen. Jb. reiss. Bot. 58, 237.

JANCZEwski, E. (1874). Observations sur la reproduction de quelques nostocacées. Ann. sci. nat. (bot.), 5 ser. 19, 119.

Lazaroff, N. \& Vishniac, W. (1961). The effect of light on the developmental cycle of Nostoc muscorum. J. gen. Microbiol. 25, 365.

Sauvageau, C. (1897). Sur le Nostoc punctiforme. Ann. sci. nat. (bot.), 8 ser. 3, 366.

Thuret, G. (1844). Note sur le mode de reproduction du Nostoc verrucosum. Ann. sci.nat. (bot.), 3 ser. 2, 319.

Fig. 4. Diagram of a postulated alternation of sporogenous and heterocystous generations by Nostoc muscorum A.

Heterocystous cycle:

1. Hormogone.

2. Motility of hormogone ceases. Intercalary cells enlarge; terminal cells become terminal heterocysts.

3. Intercalary cells divide, in a plane parallel to the axis of the hormogone.

4. It is hypothesized that four cells are initially produced from each of the intercalary cells by a process which may be reduction division. Each group of four cells or their immediate progeny are confined within a common envelope.

5-6. Each cell of the tetrad may give rise to a short filament which is capable of a limited motility.

Sporogenous cycle:

I. These filaments, at first approximately 2-4 cells in length, can develop in complete darkness. Subsequent migration and growth, to form longer filaments which fragment or produce spores, seems to require light.

II. A long sporogenous filament breaking into shorter fragments without the participation of heterocysts.

III. The terminal cells of such filaments may often be differentiated as terminal heterocysts. Fragmentation of intercalary segments of the filament to form short motile trichomes is accompanied by the formation of necridia. The intercalary cells may also become differentiated as spores (akinetes).

IV. The spores differ from the undifferentiated cells of their parent filament mainly in their less regular shape and in the possession of a denser, more refractile protoplast.

V. Germination of the spores produces 2- or 3-celled germlings which seem to be identical to the short motile trichomes produced by the fragmentation of sporogenous filaments. Since the spore germlings display the same slow motility as the fragments liberated by filament breakage it is hypothesized that the latter merely represent sections of the parent filament which are derived by germination of spores in situ.

Heterocystous cycle:

6. The short motile segments of sporogenous filaments are capable of joining 'end to end' eventually to produce heterocystous filaments. In the case of N. muscorum A growing photoautotrophically, the entire sporogenous generation is restricted to the aseriate cells produced from hormogonia. These join within their enclosing sheath, to produce the elongating heterocystous filament.

7. The sheath progressively loosens, then disintegrates as the heterocystous filament matures. Finally heterocysts and hormogonia are liberated. 


\section{EXPLANATION OF PLATES}

Photomicrographs are of unstained living material, except for fig. 12, in which the sheath is stained with methylene blue.

\section{Plate 1}

Fig. 1. Aseriate morphology exhibited when hormogonia produced in illuminated cultures are transferred to media containing glucose and incubated in complete darkness. Transfers to media containing sucrose followed by incubation in the dark produce a similar phenomenon, only if a small inoculum is employed or if the inoculum had been grown in media containing glucose in the light. $\times 650$.

Fig. 2. Sporogenous filaments. Each two-celled fragment has a common sheath which differs from the sheath of the original parent filament. The two-celled structures, which may be interpreted as two-celled spore germlings, are capable of motility after emerging from the sheath. $\times 720$.

Fig. 3. Filamentation in dark cultures. In this case the short filaments developed from a heavy inoculum incubated in media containing sucrose. Note the absence of heterocysts and the differences in size and form of these cells in comparison to the cells of heterocystous filaments. The preparation was gently crushed between slide and coverslip to break the membranes enveloping each cluster of filaments. $\times 750$.

Fig. 4. A preparation similar to that shown in fig. 3 but exposed to light for one day after the period of dark incubation. Note the fragmentation of filaments and the re-attachment of twocelled fragments. Fragmentation takes place without participation of heterocysts. $\times 1150$.

Fig. 5. Young heterocystous filaments. The expanding filaments, newly derived from the aseriate stage, reflect the fact that each cluster of filaments originated from one cell of the original filament. See fig. 1. $\times 650$.

Fig. 6. Liberation of hormogonia by heterocystous filaments. Hormogonia begin breaking away from the intercalary heterocysts, which now have a colourless, empty appearance in contrast to their former green colour. $\times 1200$.

\section{Plate 2}

Filament fusion on agar. Solid media plus glucose were seeded with homogenized suspensions of non-heterocystous filaments. The seeded agar was layered in Carrel flasks and incubated in the light at $200 \mathrm{ft} . c$. intensity.

Fig. 7. The fusion of three filaments, or possibly three filaments and a 'two-celled' stage. $\times 1000$.

Fig. 8. A later stage of 'spore' formation resulting from filament fusion. $\times 1200$.

Fig. 9. Liberation of the 'spore' $19 \mathrm{hr}$. after the photograph in fig. $8, \times 3150$.

Fig. 10. The 'head' to 'tail' attachment of a single filament yielding a closed loop containing a spore-like structure. $\times 700$.

Fig. 11. Another example of filament fusion resulting in the formation of a specialized cell. $\times 1200$.

Fig. 12. The germination of a 'spore' formed by filament fusion. $\times 1300$.

Fig. 13. Fragmentation of filaments and fusion of cells at the periphery of a sporulating colony. The debris results from the disintegration of cells which function as necridia. $\times 1200$. 

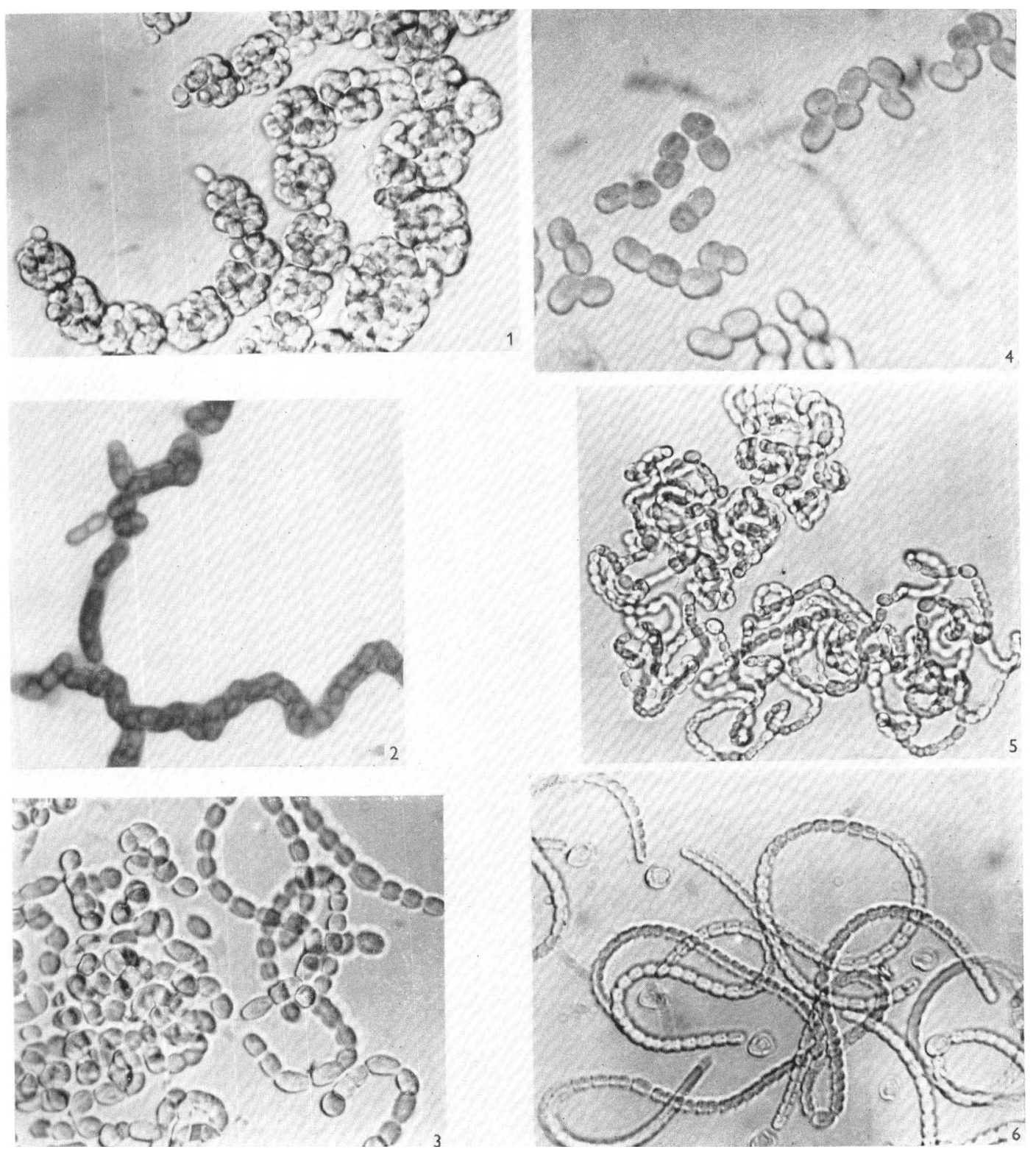

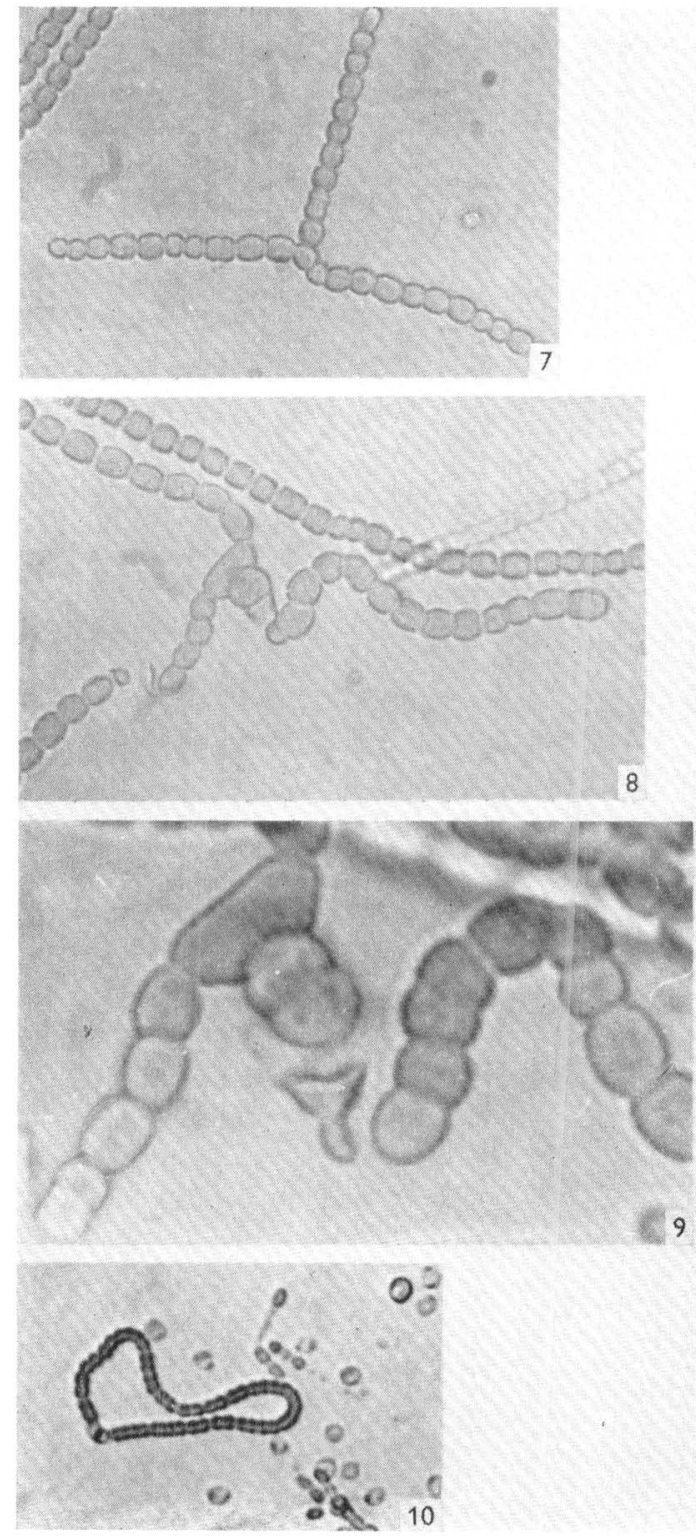
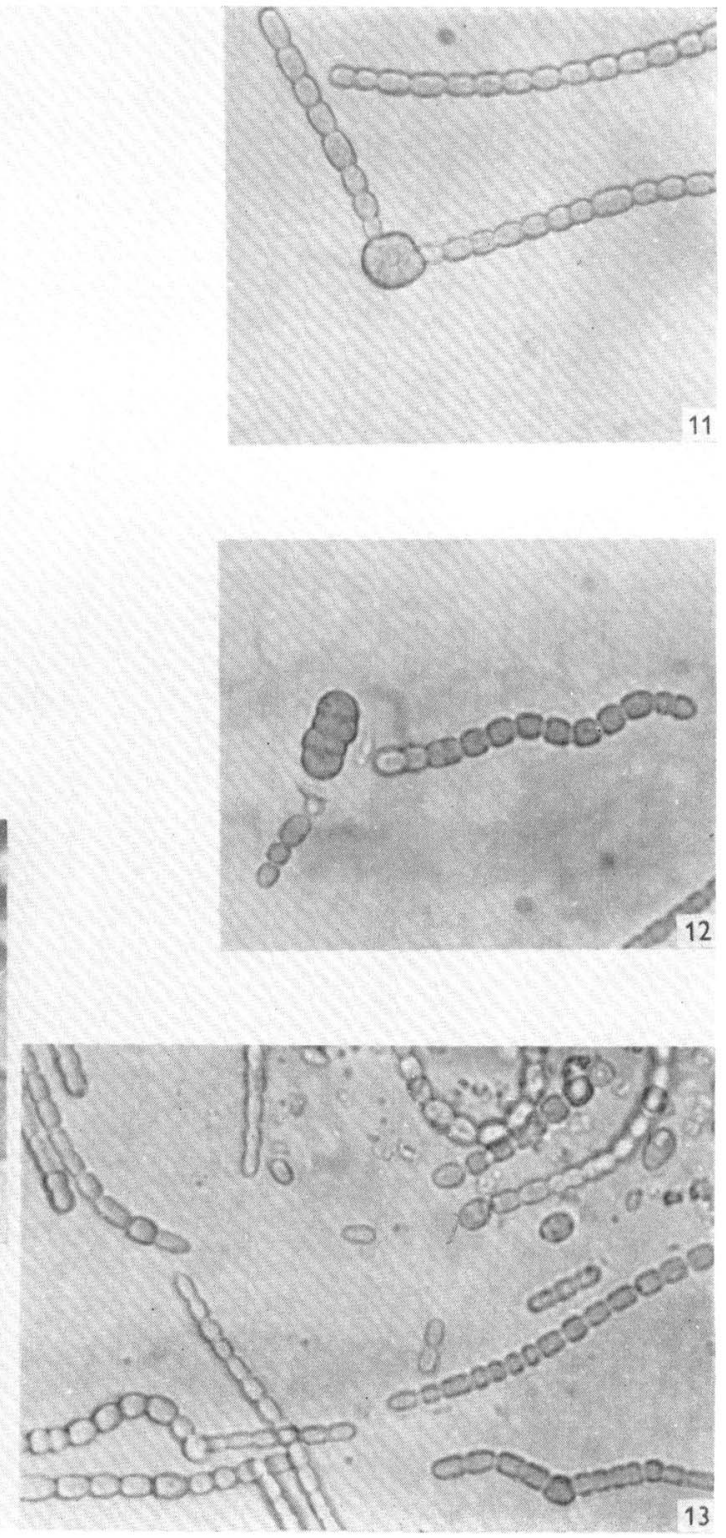